\title{
3 Research Suare \\ Predictive criteria of severe cases in COVID-19 patients of early stage
}

\section{Jinrui Gao}

Fourth Affiliated Hospital of Zhejiang University School of Medicine

\section{Xiu Huang}

Fourth Affiliated Hospital of Zhejiang University School of Medicine

\section{Haibo Gu}

Fourth Affiliated Hospital of Zhejiang University School of Medicine

\section{Lingyun Lou}

Fourth Affiliated Hospital of Zhejiang University School of Medicine

\section{Zhihao Xu ( $\nabla$ xuzhihao@zju.edu.cn )}

Fourth Affiliated Hospital of Zhejiang University School of Medicine

\section{Research Article}

Keywords: Coronavirus disease 2019 (COVID-19), SARS-CoV-2, risk factors

Posted Date: July 7th, 2020

DOI: https://doi.org/10.21203/rs.3.rs-39161/v1

License: (c) (1) This work is licensed under a Creative Commons Attribution 4.0 International License. Read Full License 


\section{Abstract}

Background: Patients with coronavirus disease 2019 (COVID-19) often suffer sudden deterioration of disease around 1 to 2 weeks after onset. Once the disease progressed to severe phase, clinical prognosis of patients will significantly deteriorate.

Methods: This was a multicenter retrospective study on patients of all adult inpatients ( $\geq 18$ years old) from Tianyou Hospital (Wuhan, China) and the Fourth Affiliated Hospital, Zhejiang University School of Medicine. All 139 patients had laboratory-confirmed COVID-19 in their early stage, which is defined as within 7 days of clinical symptoms or within 7 days of positive viral nucleic acid test for asymptomatic patients. Univariate and multivariate logistic regression models were used to determine the predictive factors in the early detection of patients who may subsequently develop into severe cases.

Results: Multivariable logistic regression analysis showed that the higher level of hypersensitivity Creactive protein ( $\mathrm{OR}=4.77,95 \% \mathrm{Cl}: 1.92-11.87, P=0.001)$, elevated alanine aminotransferase $(\mathrm{OR}=6.87$, $95 \% \mathrm{Cl}: 1.56-30.21, P=0.011)$ and chronic comorbidities (OR=11.48, 95\% $\mathrm{Cl}: 4.44-29.66, P<0.001)$ are the determining risk factors for the progression into severe pneumonia in COVID-19 patients.

Conclusion: Early COVID-19 patients with chronic comorbidities, elevated hs-CRP or elevated ALT are significantly more likely to develop severe pneumonia as the disease progresses. These risk factors may facilitate the early diagnosis of critical patients in clinical practice.

\section{Introduction}

Coronavirus disease 2019 (COVID-19) is an acute respiratory infectious disease caused by severe and highly contagious acute respiratory syndrome coronavirus 2 (SARS-CoV-2; the Coronaviridae family). Although previous studies suggested that the basic reproduction number (R0) of SARS-CoV-2 was between 2 and 3 , the countries with prompt isolation were successful in reducing the reproduction number(Wilasang et al., 2020). Extensive research has shown that the total mortality rate is $5.6 \%$, lower than SARS (13\%) and MERS (35\%)(Pormohammad et al., 2020). But the death toll has far exceeded. As of 17 June 2020, the world had 8,299,389 confirmed cases of and 446,929 deaths from COVID-19, according to publicly available data from Worldometer website.

COVID-19 patients can suddenly worsen around 1 to 2 weeks after the onset of the disease. It has previously been observed that the time from the onset of symptoms to dyspnea is 8.0 days (IQR: 5.013.0 days)(Huang et al., 2020). Once the disease progressed to a severe stage, the prognosis will be extremely poor, achieving a booming mortality rate of as high as $49.0 \%(\mathrm{Wu}$ and $\mathrm{M}, 2020)$. At the same time, recent evidence suggests that $77 \%$ of severe cases need to be admitted to ICU, while mild patients do not have such need(Liu et al., 2020). Therefore, an early identification and timely intervention of patients with tendency to become severe and critical condition is critical to improve clinical prognosis and save medical resources. What is less clear, however, is how to identify patients with severe tendency during the early stage of COVID-19. 
The objective of this study was to determine the predictive criteria of severe tendency of early COVID-19 patients by systematically analyzing the baseline clinical characteristics and laboratory indexes of severe patients and non-severe patients. Results from this study will aid in the development of an effective measures tool for the early clinical identification and intervention of severe cases in the COVID-19 outbreak.

\section{Methods}

This retrospective study enrolled a total of 139 adult inpatients with confirmed COVID-19 from Tianyou Hospital (Wuhan, China) and the Fourth Affiliated Hospital, Zhejiang University School of Medicine. All patients received complete medical history collection, vital signs measurement and laboratory and radiological examinations. The laboratory and radiological data included, but were not limited to, lymphocyte counts, hypersensitive C-reactive protein (hs-CRP), concentrations of D-dimer, erythrocyte sedimentation rate (ESR), prothrombin time (PT), procalcitonin (PCT), alanine transaminase (ALT), highsensitivity troponin T (hs-TNT) and chest CT images. Related data were collected and cross-checked by two doctors to assure the data quality. COVID-19 patients of early stage are defined as within 7 days of clinical symptoms or within 7 days of positive viral nucleic acid test for asymptomatic patients.

Patients who had any of the following features at the time of, or after admission were classified as severe cases: (a) respiratory distress ( $\geq 30$ breaths per minute); (b) oxygen saturation at rest $\leq 93 \%$; (c) oxygenation index (artery partial pressure of oxygen/inspired oxygen fraction, $\mathrm{PaO}_{2} / \mathrm{FiO}_{2}$ ) $\leq 300 \mathrm{mmHg}$; (d) Lung imaging showed that the lesion progressed more than $50 \%$ within 24 hours and 48 hours. As a result, there were 93 cases in the severe group and 46 cases in the non-severe group. Statistical analyses were performed using SPSS 20.0 software. Univariate and multivariate logistic regression models were used to analyze the risk factors for severe tendency of early COVID-19 patients.

\section{Results}

As indicated in Table 1, the median age of patients was 60 years (IQR, 47-69; range from 19 to 89 years). The age of the patients in the severe group was older than that in the non-severe group $(P<0.001) .52 \%$ of the patients are male, while no significant correlation between sex and severity of the disease $(P=0.059)$ was found. 76 patients were complicated with chronic comorbidities, of which hypertension (32\%) was the most common, followed by chronic obstructive pulmonary disease (17\%) and diabetes (15\%). There was no significant difference in antiviral therapy, antibiotic therapy, oxygen therapy and traditional Chinese medicine treatment between two groups ( $P>0.05)$, but patients in the severe group were more likely to receive glucocorticoid therapy $(P=0.012)$. Lymphocyte count was significantly lower in severe group than the non-severe group (0.93 vs 1.2, $P=0.001)$. In addition, the severe group showed the significantly higher levels of hs-CRP $(P<0.001)$, D-dimer $(P<0.035)$ and ALT $(P<0.001)$. Although a statistical difference was observed in the level of LDH between the two groups $(P=0.01)$, if we take the upper limit of normal value $(250 \mathrm{U} / L)$ as a standard, the difference was insignificant $(P=0.33)$. Lung lesions in the chest CT images were detected for all patients. The imaging manifestation of severe 
patients and non-severe patients were different $(P<0.001)$. In the severe group, bilateral lung lesions were more common (92\%).

As presented in Table 2, the advanced age ( $\geq 65$ years old), chronic comorbidities, lymphocytopenia, elevated hs-CRP, increased D-dimer and elevated levels of ALT were the risk factors for the progression of COVID-19 patients into their severe stage. Further multivariate logistic regression analysis demonstrated chronic comorbidities (OR $=11.48,95 \% \mathrm{Cl}: 4.44-29.66, P=0.001)$, elevated hs-CRP $(\mathrm{OR}=4.77$, $95 \% \mathrm{Cl}: 1.92-11.87, P=0.001)$ and elevated $\mathrm{ALT}(\mathrm{OR}=6.87,95 \% \mathrm{Cl}: 1.56-30.21, \mathrm{P}=0.011)$ were key risk factors for the tendency of severe phase.

\section{Discussion}

Our study provides some important insight into the differentiation of severe cases among the early COVID-19 patients. The presence of chronic comorbidity is a key risk factor of developing into severe state. Recent study demonstrated that presence of hypertension, diabetes, COPD and coronary artery disease were risk factors of disease progression in mild or moderate COVID-19 patients, which is in accordance with our result(Cen et al., 2020). Moreover, patients with two or more comorbidities are prone to poor prognosis compared with those with no or single(Guan et al., 2020). The risk of severe predisposition in patients with chronic comorbidities is higher since it may be related to subsequent multiple organ function damage caused by SARS-CoV-2. Principally, increased gene expression of ACE2 in the airways of COPD patients may explain the susceptibility of SARS-CoV-2 and exacerbation of disease(Leung et al., 2020). Also, SARS-CoV-2 facilitated impaired insulin secretion through ACE2 in pancreatic endocrine cells, meanwhile diabetic patients are susceptible to viral infections, causing cytokine storms and worsening clinical presentation(Maddaloni and Buzzetti, 2020).

Our research suggested that the risk of severe illness increased with an elevated level of hs-CRP. It has been noticed that dysregulation of inflammatory cytokines and chemokines contributes to severe COVID19. And the cytokine storm can induce apoptosis of endothelial cells and epithelial cells, which may cause vascular leakage and alveolar edema and lead to respiratory failure(Ye et al., 2020). CRP, stimulated by the release of cytokines, may reflect the severity of lung damage. Previous researchers have found that elevated hs-CRP is related to respiratory function and lung lesions(Erika et al., 2020, Wang, 2020). CRP could be a promising biomarker for assessing disease lethality. And many researches in other countries, like Singapore and Norway, have gotten the same results with us(Bao et al., 2020).

Multivariate logistic regression analysis demonstrated that patients with an elevated level of ALT had a higher risk of exacerbation. It should be noted that the laboratory data used in our study were from early COVID-19 patients, generally before or shortly after medication. Thus, the elevated ALT is more likely the result of virus-related liver cell injury instead of drug-related cause. At the same time, the liver histological examination of patients with COVID-19 showed hepatocyte degeneration and necrosis, but no observed infection of SARS-CoV-2 in liver tissue(Yao et al., 2020). These evidences suggest that liver abnormalities in COVID-19 patients may be due to systemic inflammatory response-induced liver injuries 
and patients with early elevation of ALT may suffer the damage of cytokine storm and excessive immune response. Similarly, Bao et al. also concluded in a meta-analysis on 35 studies including 5912 COVID-19 positive patient that ALT could predict the progress of the COVID-19 changes(Bao, et al., 2020).

Note that, like other retrospective studies in commonplace, the clinical data of some patients may not be all inclusive; thus, the effect of other factors may be overlooked, such as coronary heart disease.

Regarding the correlation between AST, ESR, LDH and PCT and the prognosis of patients, the discrepancy from the earlier studies may be related to the different time of data collection(Bao, et al., 2020, Huang, et al., 2020, Zhang et al., 2020). Our data were collected from the early stage of COVID-19 patients due to the nature of our design inherent to this study. In addition, if this study were to include data from dead patients, a wider spectrum of potentially underestimated factors may be examined.

\section{Conclusion}

Early COVID-19 patients with chronic comorbidities, elevated hs-CRP or increased ALT are significantly more likely to develop severe pneumonia as disease progresses. If a patient's profile fits one of these three criteria, it will become highly important to raise priority for the critical care and surveillance of disease progress of the patient. Our findings may facilitate the early recognition of critical patients in clinical practice in dealing with this unprecedent COVID-10 outbreak.

\section{Declarations}

\section{Contributions:}

Zhihao Xu conceived and designed the study. Jinrui Gao designed the study, analyzed the data and wrote the first draft of the manuscript. Xiu Huang analyzed the data and wrote the first draft of the manuscript. Haibo Gu collected the clinical and CT data. Lingyun Lou did the analysis. All authors have read and approved the final manuscript and, therefore, have full access to all the data in the study and take responsibility for the integrity and security of the data.

\section{Compliance with ethics guidelines}

There were no conflicts of interest to this work.

This study was approved by the ethics committee of the Fourth Affiliated Hospital of Zhejiang University School of Medicine [K20200024]. All procedures followed were in accordance with the ethical standards of the responsible committee on human experimentation (institutional and national) and with the Helsinki Declaration of 1975, as revised in 2008(5). Informed consent was obtained from all patients for being included in the study. 


\section{Funding}

This work was supported by the Jinhua special scientific research fund for COVID-19 prevention and control [2020XG-31]; Zhejiang University special scientific research fund for COVID-19 prevention and control [2020XGZX069].

Competing interests: The authors declare no competing interests.

\section{References}

1. Bao, J., Li, C., Zhang, K., Kang, H., Chen, W. and Gu, B., 2020. Comparative analysis of laboratory indexes of severe and non-severe patients infected with COVID-19, Clin Chim Acta. https://doi.org/10.1016/j.cca.2020.06.009

2. Cen, Y., Chen, X., Shen, Y., Zhang, X.H., Lei, Y., Xu, C., et al., 2020. Risk factors for disease progression in mild to moderate COVID-19 patients- a multi-center observational study, Clin Microbiol Infect. https://doi.org/10.1016/j.cmi.2020.05.041

3. Erika, P., Domenica, Z., Paolo, I., Luca, R., Giulia, L., Alessandro, D., et al., 2020. Lactate dehydrogenase and C-reactive protein as predictors of respiratory failure in CoVID-19 patients, Clin Chim Acta 509(135-8. https://doi.org/10.1016/j.cca.2020.06.012

4. Guan, W.J., Liang, W.H., Zhao, Y., Liang, H.R., Chen, Z.S., Li, Y.M., et al., 2020. Comorbidity and its impact on 1590 patients with COVID-19 in China: a nationwide analysis, Eur Respir J 55(5). https://doi.org/10.1183/13993003.00547-2020

5. Huang, C., Wang, Y., Li, X., Ren, L., Zhao, J., Hu, Y., et al., 2020. Clinical features of patients infected with 2019 novel coronavirus in Wuhan, China, Lancet 395(10223):497-506. https://doi.org/10.1016/s0140-6736(20)30183-5

6. Leung, J.M., Yang, C.X., Tam, A., Shaipanich, T., Hackett, T.L., Singhera, G.K., et al., 2020. ACE-2 expression in the small airway epithelia of smokers and COPD patients: implications for COVID-19, Eur Respir J 55(5). https://doi.org/10.1183/13993003.00688-2020

7. Liu, Y., Yan, L.M., Wan, L., Xiang, T.X., Le, A., Liu, J.M., et al., 2020. Viral dynamics in mild and severe cases of COVID-19, Lancet Infect Dis 6):656-657. https://doi.org/10.1016/s1473-3099(20)30232-2

8. Maddaloni, E. and Buzzetti, R., 2020. Covid-19 and diabetes mellitus: unveiling the interaction of two pandemics, Diabetes Metab Res Rev:e33213321. https://doi.org/10.1002/dmrr.3321

9. Pormohammad, A., Ghorbani, S., Khatami, A., Farzi, R., Baradaran, B., Turner, D.L., et al., 2020. Comparison of confirmed COVID-19 with SARS and MERS cases - Clinical characteristics, laboratory findings, radiographic signs and outcomes: A systematic review and meta-analysis, Rev Med Virol:e2112. https://doi.org/10.1002/rmv.2112

10. Wang, L., 2020. C-reactive protein levels in the early stage of COVID-19, Med Mal Infect 50(4):332334. https://doi.org/10.1016/j.medmal.2020.03.007 
11. Wilasang, C., Sararat, C., Jitsuk, N.C., Yolai, N., Thammawijaya, P., Auewarakul, P., et al., 2020. Reduction in effective reproduction number of COVID-19 is higher in countries employing active case detection with prompt isolation, J Travel Med. https://doi.org/10.1093/jtm/taaa095

12. Wu, Z. and M, M.J., 2020. Characteristics of and Important Lessons From the Coronavirus Disease 2019 (COVID-19) Outbreak in China: Summary of a Report of 72314 Cases From the Chinese Center for Disease Control and Prevention, Jama. https://doi.org/10.1001/jama.2020.2648

13. Yao, X.H., Li, T.Y., He, Z.C., Ping, Y.F., Liu, H.W., Yu, S.C., et al., 2020. A pathological report of three COVID-19 cases by minimal invasive autopsies, Zhonghua Bing Li Xue Za Zhi 49(5):411-417. https://doi.org/10.3760/cma.j.cn112151-20200312-00193

14. Ye, Q., Wang, B. and Mao, J., 2020. The pathogenesis and treatment of the 'Cytokine Storm' in COVID19, J Infect 80(6):607-613. https://doi.org/10.1016/j.jinf.2020.03.037

15. Zhang, J.J., Dong, X., Cao, Y.Y., Yuan, Y.D., Yang, Y.B., Yan, Y.Q., et al., 2020. Clinical characteristics of 140 patients infected with SARS-CoV-2 in Wuhan, China, Allergy. https://doi.org/10.1111/all.14238

\section{Tables}

Table1. Clinical features of patients with COVID-19 


\begin{tabular}{|c|c|c|c|c|}
\hline & $\begin{array}{l}\text { Total } \\
(\mathrm{N}=139)\end{array}$ & $\begin{array}{l}\text { Non-severe } \\
(\mathrm{N}=46)\end{array}$ & $\begin{array}{l}\text { Severe } \\
(\mathrm{N}=93)\end{array}$ & $\begin{array}{l}P \\
\text { Value }\end{array}$ \\
\hline Age (year),median (IQR) & $60.0(47.0-69.0)$ & $48.0(34.0-63.0)$ & $62.0(53.0-69.0)$ & $<0.001$ \\
\hline \multicolumn{5}{|l|}{$\operatorname{sex}$} \\
\hline female & $67(48 \%)$ & $27(59 \%)$ & $40(43 \%)$ & \multirow[t]{2}{*}{0.059} \\
\hline male & $72(52 \%)$ & $19(41 \%)$ & $53(57 \%)$ & \\
\hline Chronic comorbidities & $76(55 \%)$ & $11(24 \%)$ & $65(70 \%)$ & $<0.001$ \\
\hline Hypertension & $42(30 \%)$ & $7(15 \%)$ & $35(38 \%)$ & 0.005 \\
\hline Diabetes & $21(15 \%)$ & $1(2 \%)$ & $20(22 \%)$ & 0.001 \\
\hline Coronary artery disease & $16(12 \%)$ & $3(7 \%)$ & $13(14 \%)$ & 0.26 \\
\hline COPD & $23(17 \%)$ & $3(7 \%)$ & $20(22 \%)$ & 0.029 \\
\hline other & $12(9 \%)$ & $3(7 \%)$ & $9(10 \%)$ & 0.57 \\
\hline \multicolumn{5}{|l|}{ Treatment } \\
\hline Glucocorticoid therapy & $22(16 \%)$ & $2(4 \%)$ & $20(22 \%)$ & 0.012 \\
\hline Antiviral treatment & $82(59 \%)$ & $32(70 \%)$ & $50(54 \%)$ & 0.10 \\
\hline Antibiotic therapy & $45 \rrbracket 32 \% \rrbracket$ & $10(22 \%)$ & $35(38 \%)$ & 0.082 \\
\hline Oxygen therapy & $139 \unrhd 100 \% \rrbracket$ & $46(100 \%)$ & $93(100 \%)$ & 1 \\
\hline $\begin{array}{l}\text { Traditional Chinese } \\
\text { medicine } \\
\text { therapy }\end{array}$ & $139 \rrbracket 100 \% \rrbracket$ & $46(100 \%)$ & $93(100 \%)$ & 1 \\
\hline WBC $\left(\times 10^{9} / \mathrm{L}\right)$ & $5.6(2.9-8.6)$ & 4.98(3.3-6.3) & $5.9(3.0-8.7)$ & 0.062 \\
\hline$<4$ & $39(28 \%)$ & $15(32 \%)$ & $24(26 \%)$ & 0.62 \\
\hline $4-10$ & $96(69 \%)$ & $30(65 \%)$ & $66(71 \%)$ & $\ldots$ \\
\hline$>10$ & $4(3 \%)$ & $1(2 \%)$ & $3(3 \%)$ & $\ldots$ \\
\hline Lymphocyte count $\left(\times 10^{9} / \mathrm{L}\right)$ & $1.01(0.77-1.4)$ & $1.2(0.94-1.6)$ & $0.93(0.60-1.3)$ & 0.001 \\
\hline$<0.8$ & $39(28 \%)$ & $6(13 \%)$ & $33(35 \%)$ & 0.004 \\
\hline Anemia & $10(7 \%)$ & $4(9 \%)$ & $6(6 \%)$ & 0.43 \\
\hline $\mathrm{ESR}(\mathrm{mm} / \mathrm{h})$ & $38.5(21.8-60.5)$ & $39.1(26.2-56.4)$ & $38.5(20.8-64)$ & 0.349 \\
\hline Hs-CRP (mg/L) & $26.8(5.1-46.4)$ & $5.05(1.4-27.25)$ & $35.1(12.8-60.1)$ & $<0.001$ \\
\hline
\end{tabular}




\begin{tabular}{|c|c|c|c|c|}
\hline$<10$ & $56(40 \%)$ & $28(61 \%)$ & $28(30 \%)$ & $<0.001$ \\
\hline $10-50$ & $53(38 \%)$ & $16(35 \%)$ & $37(40 \%)$ & $\ldots$ \\
\hline$>50$ & $30(22 \%)$ & $2(4 \%)$ & $28(30 \%)$ & $<0.001$ \\
\hline PT (s) & $12.0(11.3-12.6)$ & $10.9(11.6-12.3)$ & $12.2(11.6-13.1)$ & 0.052 \\
\hline$>16$ & $7(5 \%)$ & $1(2 \%)$ & $6(6 \%)$ & 0.26 \\
\hline D-dimer $(\mu \mathrm{g} / \mathrm{mL})$ & $0.5(0.08-1.4)$ & $0.20(0.01-0.57)$ & $0.67(0.15-1.80)$ & 0.035 \\
\hline$>0.5$ & $47(34 \%)$ & $9(20 \%)$ & $38(41 \%)$ & 0.009 \\
\hline $\mathrm{CK}(\mathrm{U} / \mathrm{L})$ & $60(35.5-133)$ & $54(34-120)$ & $61(37-155)$ & 0.78 \\
\hline $\mathrm{LDH}(\mathrm{U} / \mathrm{L})$ & 243(194-314) & $212(162-266)$ & $274(219-369)$ & 0.01 \\
\hline$>250$ & $41(29 \%)$ & $11(24 \%)$ & $30(32 \%)$ & 0.33 \\
\hline Creatinine $(>110 \mu \mathrm{mol} / \mathrm{L})$ & $7(5 \%)$ & $1(2 \%)$ & $6(6 \%)$ & 0.43 \\
\hline $\operatorname{ALT}(\mathrm{U} / \mathrm{L})$ & $24(18-46)$ & $19.5(14-28)$ & $27(20-54)$ & $<0.001$ \\
\hline$>50 U / L$ & $22(16 \%)$ & $3(6 \%)$ & $19(20 \%)$ & 0.026 \\
\hline Hs-TNT (ng/mL) & $\begin{array}{l}0.004(0.00- \\
0.015)\end{array}$ & $\begin{array}{l}0.004(0.00- \\
0.008)\end{array}$ & $\begin{array}{l}0.005(0.00- \\
0.021)\end{array}$ & 0.166 \\
\hline PCT (ng/mL) & $0.03(0.01-0.04)$ & $0.029(0.01-0.04)$ & $0.03(0.02-0.045)$ & 0.316 \\
\hline \multicolumn{5}{|l|}{ CT positive } \\
\hline Bilateral lungs & $114(82 \%)$ & $28(61 \%)$ & $86(92 \%)$ & $<0.001$ \\
\hline
\end{tabular}

Abbreviations: COPD, Chronic obstructive lung disease; WBC, white blood cell count; ESR, erythrocyte sedimentation rate; hs-CRP, hypersensitive C-reactive protein; $\mathrm{PT}$, prothrombin time; CK creatine kinase; LDH, lactate dehydrogenase; ALT, alanine transaminase; hs-TNT, high-sensitivity troponin T; PCT, procalcitonin.

Data are median (IQR), $\mathrm{n}(\%)$, or $\mathrm{n} / \mathrm{N}(\%)$. $P$ values were calculated by Mann-Whitney $\mathrm{U}$ test, $\chi^{2}$ test, or Fisher's exact test, as appropriate.

Table 2. Risk factors associated with severe cases of COVID-19 patients 


\begin{tabular}{|c|c|c|c|c|}
\hline & \multicolumn{2}{|c|}{ Univariate analysis } & \multicolumn{2}{|c|}{ Multivariate analysis } \\
\hline & OR $(95 \% \mathrm{Cl})$ & $\begin{array}{l}P \\
\text { value }\end{array}$ & OR $(95 \% \mathrm{Cl})$ & $\begin{array}{l}P \\
\text { value }\end{array}$ \\
\hline Age ( $₫ 65$ years vs $\geq 65$ years) & $2.72(1.21-6.12)$ & 0.015 & $\ldots$ & $\ldots$ \\
\hline Chronic comorbidities $\llbracket$ yes vs no $\rrbracket$ & $\begin{array}{l}7.39(3.28- \\
16.60)\end{array}$ & $<0.001$ & $\begin{array}{l}11.48(4.44- \\
29.66)\end{array}$ & $<0.001$ \\
\hline Hypertension & $3.36(1.36-8.33)$ & 0.005 & $\ldots$ & $\ldots$ \\
\hline Diabetes & $\begin{array}{l}12.33(1.59- \\
95.05)\end{array}$ & 0.01 & $\ldots$ & $\ldots$ \\
\hline COPD & $\begin{array}{l}3.92(1.10- \\
13.99)\end{array}$ & 0.006 & $\ldots$ & $\ldots$ \\
\hline Coronary artery disease & $\begin{array}{l}2.07(0.42- \\
10.17)\end{array}$ & 0.26 & $\ldots$ & $\ldots$ \\
\hline $\begin{array}{l}\text { Lymphocyte count }\left(\left(<0.8 \times 10^{9} / \mathrm{L} \text { vs }\right.\right. \\
\left.\geq 0.8 \times 10^{9} / \mathrm{L}\right)\end{array}$ & $3.67(1.41-9.55)$ & 0.038 & $\ldots$ & $\cdots$ \\
\hline Hs-CRP (mg/L) & & & $\ldots$ & $\ldots$ \\
\hline$<10$ vs $\geq 10$ & $3.61(1.72-7.57)$ & 0.001 & $\begin{array}{l}4.77(1.92- \\
11.87)\end{array}$ & 0.001 \\
\hline$<50$ vs $\geq 50$ & $\begin{array}{l}9.48(2.15- \\
41.83)\end{array}$ & 0.003 & $\ldots$ & $\ldots$ \\
\hline D-dimer $(<0.5 \mu \mathrm{g} / \mathrm{mL} v s \geq 0.5 \mu \mathrm{g} / \mathrm{mL})$ & $2.84(1.23-6.56)$ & 0.015 & $\ldots$ & $\ldots$ \\
\hline $\operatorname{ALT}(<50 \mathrm{U} / \mathrm{L}$ vs $\geq 50 \mathrm{U} / \mathrm{L})$ & $\begin{array}{l}3.68(1.03- \\
13.11)\end{array}$ & 0.045 & $\begin{array}{l}6.87(1.56- \\
30.21)\end{array}$ & 0.011 \\
\hline
\end{tabular}

Abbreviations: COPD, Chronic obstructive lung disease; hs-CRP, hypersensitive C-reactive protein; ALT, alanine transaminase. 